\title{
Location and search via the web of hydrometric information of the Mexican National Hydrometric Network
}

\author{
Y. Solís-Alvarado ${ }^{1}$, H. Sanvicente-Sánchez ${ }^{1}$, \\ J. García-Hernández ${ }^{2}$, G. Martínez-Castillo ${ }^{2}$ \\ \& R. Mendoza-Betanzos ${ }^{2}$ \\ ${ }^{I}$ Subcoordinación de Hidrología Superficial, \\ Instituto Mexicano de Tecnología del Agua, México \\ ${ }^{2}$ Independent Consultant, México
}

\begin{abstract}
Measurement of surface water is critical to quantify rain, which provides support to studies related to climate change, such as: hydrological studies, mathematical models, establishment of vulnerable areas as a consequence of extreme weather events, etc.; the Mexican national database called BANDAS (Banco Nacional de Datos de Aguas Superficiales) integrates the national hydrometric network. BANDAS records the water level (scales) and the amount of water passing in a specific time (gauging) in the main Mexican rivers, from all the non-automatic hydrometric stations in Mexico; BANDAS has historical information about daily, monthly and annual average flow. This paper shows a web application named SIG Bandas v 1.0 which allows people to locate and make queries about the Mexican hydrometric network without charge. People can check the location of any hydrometric station; to know the period of years recorded by it, download historical data, descriptive records and, in some cases, the image of the station. Additionally, but only for users with password, it allows the updating of information on the hydrometric network. SIG Bandas $v 1.0$ permits the distribution of hydrometric data to many users such as students from universities, consulting firms, government agencies, etc.

Keywords: National Hydrometric Network, hydrometric calculus, gauging. Red Hidrométrica Nacional, cálculo hidrométrico, gasto.
\end{abstract}




\section{Introduction}

Measurement of surface water is critical to quantify rain, which provides support to studies related to climate change, such as: hydrological studies mathematical models, establishment of vulnerable areas as a consequence of extreme weather events, etc.; in México, the digital management of hydrometric information is widely used for the management of water resources, for that reason, the National Water Commission (Conagua), through the Mexican Institute of Water Technology (IMTA) has been updating the national database called BANDAS (Banco Nacional de Datos de Aguas Superficiales) which integrates the Conagua's national hydrometric network.

The water level (scales) is recorded in BANDAS along with the amount of water passing in a specific time (gauging) in the Mexico's main rivers. BANDAS has registered all the non-automatic hydrometric stations in Mexico; BANDAS has historical information about average daily, monthly and annual average flow. The historical data registered on BANDAS is generated through an extensive process of hydrometric calculation [1].

The Mexican Institute of Water Technology (IMTA) has developed a web application named SIG Bandas v 1.0 to locate and query the Mexican hydrometric network, which allows people without any charge, to check the location of any hydrometric station belonging to the Conagua's national hydrometric network.

SIG Bandas $v 1.0$ allows anybody to know the period of years recorded, downloading historical data about gauging and scales from the station and descriptive record, such as: name, id, state, river, etc. and, in some cases, the image of the station. Additionally, but only for users with password, it allows the updating of information on the hydrometric network. Using SIG Bandas v 1.0 has widely allowed the distribution of hydrometric data to many users such as students from universities, consulting firms, government agencies, etc.

\section{SIG Bandas tool}

The web application SIG Bandas $v 1.0$ uses the BANDAS's database which is described in section 2.1 This database includes at least six main files, including daily, monthly and annual data. In section 2.2, the interface of SIG Bandas v 1.0 is described.

\subsection{BANDAS database}

The last version of BANDAS database has been migrated to Microsoft Access, because it is the most popular database manager that a lot of people have in their computer in México. For some stations, the earlier data comes from 1910, but little by little the number of stations registering scales and gauging in rivers have been increased. Unfortunately BANDAS is updated approximately every tree years, so the last updated version has been until 2011.

Each station has an identification key named CLAVE, which is created joining two numbers from 01 to 37 corresponding to the hydrologic region number (RH), 
with a consecutive number in each RH; there are $37 \mathrm{RH}$ around the country. Figure 1 represents a list of all the files which integrate this database and the table's name contained in an mdb file, e.g. station $36082 . \mathrm{mdb}$ means that this station exists in the hydrologic region number 36 and there exists at least 81 registered stations before the station number 82 and it contains six main tables: DA36082 (annual data), DM36082 (monthly data), DD36082 (daily data), HD36082 (Hydrogram data), LI36082 (Limnigraph data) and ST36082 (Sediment data).

\begin{tabular}{|c|c|c|c|c|c|c|c|}
\hline \multirow{7}{*}{$\begin{array}{l}401,408 \\
503,808 \\
323,584 \\
859,008 \\
218,880 \\
403,200 \\
952,064 \\
028,096\end{array}$} & \multirow{3}{*}{$\frac{01002 \cdot \mathrm{mdb}}{01007 \cdot \mathrm{mdb}}$} & \multicolumn{6}{|c|}{ A $\mid$ a -4$) \div=36082:$ Base de datos (Fc } \\
\hline & & \multicolumn{2}{|c|}{ Archivo Inicio } & Crear & \multicolumn{2}{|c|}{ Datos externos } & \multirow{2}{*}{$\begin{array}{c}\text { Herram } \\
\text { as }\end{array}$} \\
\hline & & 8 & 题 & & $\nabla=$ & 圈 & \\
\hline & $\frac{01022 \cdot \mathrm{mdb}}{01023 \cdot \mathrm{mdb}}$ & Ver & Porta & & & 05 & 5 Buscal \\
\hline & $01024 . \mathrm{mdb}$ & ver & & & y filtrar & & 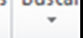 \\
\hline & $01025 . \mathrm{mdb}$ & Vistas & & & & & \\
\hline & $\frac{01026 \cdot \mathrm{mdb}}{01027 \cdot \mathrm{mdb}}$ & Todas | & las tabla & & & ( ) « & \\
\hline 729,088 & $\overline{01028 . \mathrm{mdb}}$ & DA360 & & & & $\hat{\hat{n}}$ & \\
\hline 700,416 & $01029 . \mathrm{mdb}$ & & & & & & \\
\hline 348,160 & $01031 . \mathrm{mdb}$ & 曲 D & A36082: T & Tabla & & & \\
\hline 897,024 & $01034 . \mathrm{mdb}$ & DCG36 & 5082 & & & $\hat{\imath}$ & \\
\hline 860,160 & $01036 . \mathrm{mdb}$ & 囲 D & CG36082: & : Tabla & & & \\
\hline 634,880 & $01039 . \mathrm{mdb}$ & DD360 & & & & $\hat{\imath}$ & \\
\hline & & 囲 D & D36082: & Tabla & & & \\
\hline & & DM360 & 082 & & & $\hat{\imath}$ & \\
\hline $2,600,960$ & $\overline{36082 . \mathrm{mdb}}$ & 圈 D & M36082: & Tabla & & & \\
\hline 344,064 & $36083 . \mathrm{mdb}$ & HD360 & & & & $\hat{\imath}$ & \\
\hline $\begin{array}{l}458,752 \\
729,088\end{array}$ & $\frac{36084 . \mathrm{mdb}}{36089 \cdot \mathrm{mdb}}$ & 贯 & D36082: & Tabla & & & \\
\hline 466,944 & $36090 . \mathrm{mdb}$ & ICG360 & 082 & & & $\hat{\hat{\lambda}}$ & \\
\hline $4,624,384$ & $37005 \cdot \mathrm{mdb}$ & 典 IC & G36082: & Tabla & & & \\
\hline $3,719,168$ & $37007 . \mathrm{mdb}$ & LG3608 & & & & $\hat{\hat{\imath}}$ & \\
\hline $\begin{array}{r}1,974,272 \\
598,016\end{array}$ & $\frac{37008 \cdot \mathrm{mdb}}{37011 . \mathrm{mdb}}$ & 西 LC & G36082: $\mathrm{T}$ & Tabla & & & \\
\hline $1,155,072$ & $37012 . \mathrm{mdb}$ & LI3608. & & & & $\hat{\imath}$ & \\
\hline $1,904,640$ & $\frac{37013 \cdot \mathrm{mdb}}{37014 \cdot \mathrm{mdh}}$ & 单 u & $36082: \mathrm{Ta}$ & bla & & & \\
\hline $\begin{array}{l}573,440 \\
438,272\end{array}$ & $\frac{37014 \cdot \mathrm{mdb}}{37015 \cdot \mathrm{mdb}}$ & ST3608 & & & & $\hat{\imath}$ & \\
\hline & & 政 & $36082: \mathrm{T}$ & & & & \\
\hline
\end{tabular}

Figure 1: Files which integrate the BANDAS database and tables from each station.

Those tables contain all the historic records of all the years that the station has been recording [2]. Figure 2 shows an example of the three main tables used to share BANDAS's information; a) shows the next main fields for a year recorded: year of the record (pk_anio), maximum gauge (ngasto_mxa), maximum scale reading (nlect_gmxa), runoff volume (nvolum_esc); b) shows the next main fields for a month recorded: year of the record (pk_anio), month of the record (pk_mes), maximum gauge (ngasto_mxm), day which presents the maximum gauge (ndia_gmxm), hour in the day when the maximum gauge was presented (nhora_gmxm), maximum scale reading of the maximum gauge (nlect_gmxm), the same variables but in their minimum values (ngasto_min, ndia_gmin, nhora_gmin, nlect_gmin), and runoff volume (nvolum_esc). 


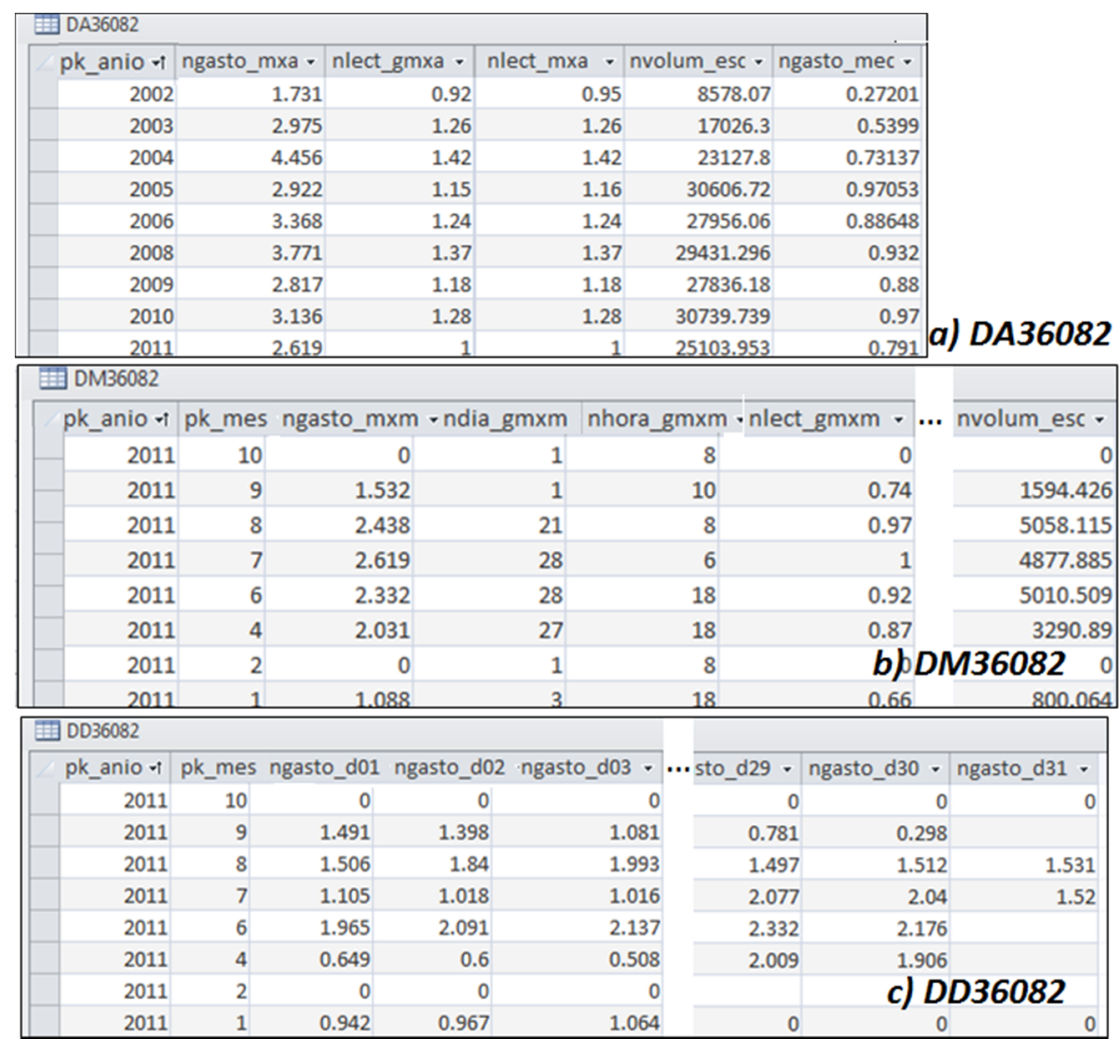

Figure 2: Example of the fields recorded by year for each station. In this case station 36082 .

Finally, c) shows the next main fields for a day recorded: year of the record ( $\mathrm{pk}$ _anio), month of the record (pk_mes), gauge of day number one in the month (ngasto_d01), gauge of day number two in the month (ngasto_d02) and so on until the last day in the month.

Besides this information, there is another very important field used in order to identify a station and to know where is geographically located, and of course to query this information. BANDAS has an inventory as a catalogue which describes the name of the river, basin, sub-basin, hydrologic region, state, latitude and longitude coordinates.

\subsection{Interface}

SIG Bandas v 1.0 application was developed under the Visual Studio 2010 platform, in ASP .net (C\#) language [3]; in a server with Windows Server 2008 operating system, Google Maps JavaScript API v3 [4-6], and the SQL server express database manager [7]. SQL server express is used just to administrate resources like images and the users; there are guests and registered users. 
Hydrometric data is stored by Microsoft Access and it is transferred from the server to the user local PC. The web address to consult it is: http:/hidrosuperf.imta.mx/bandas/, located at IMTA's building.

SIG Bandas's home screen is divided into two sections, as is shown in Figure 3. The first section lets users to choose the layer to be displayed either hydrometric stations layer or dams layer. Besides, it displays the thirteen Administrative Hydrologic Regions (RHA) México has, with their hydrometric stations, in order to turn on the check button to display either station or dams of the RHA studied. On the top of the screen there is a grey line where users can search for a specific station or dam just writing its CLAVE, as is shown in Figure 4; look after the coordinate position, and it lets users to sign into the system. The second section is a graphic one where the Google Map is displayed (location: México). Once SIG Bandas $v 1.0$ identifies the stations geographically, it makes a zoom to its location in the map. Active hydrometric station are displayed as green dots and active dams are displayed as green squares, rivers are displayed as blue lines.

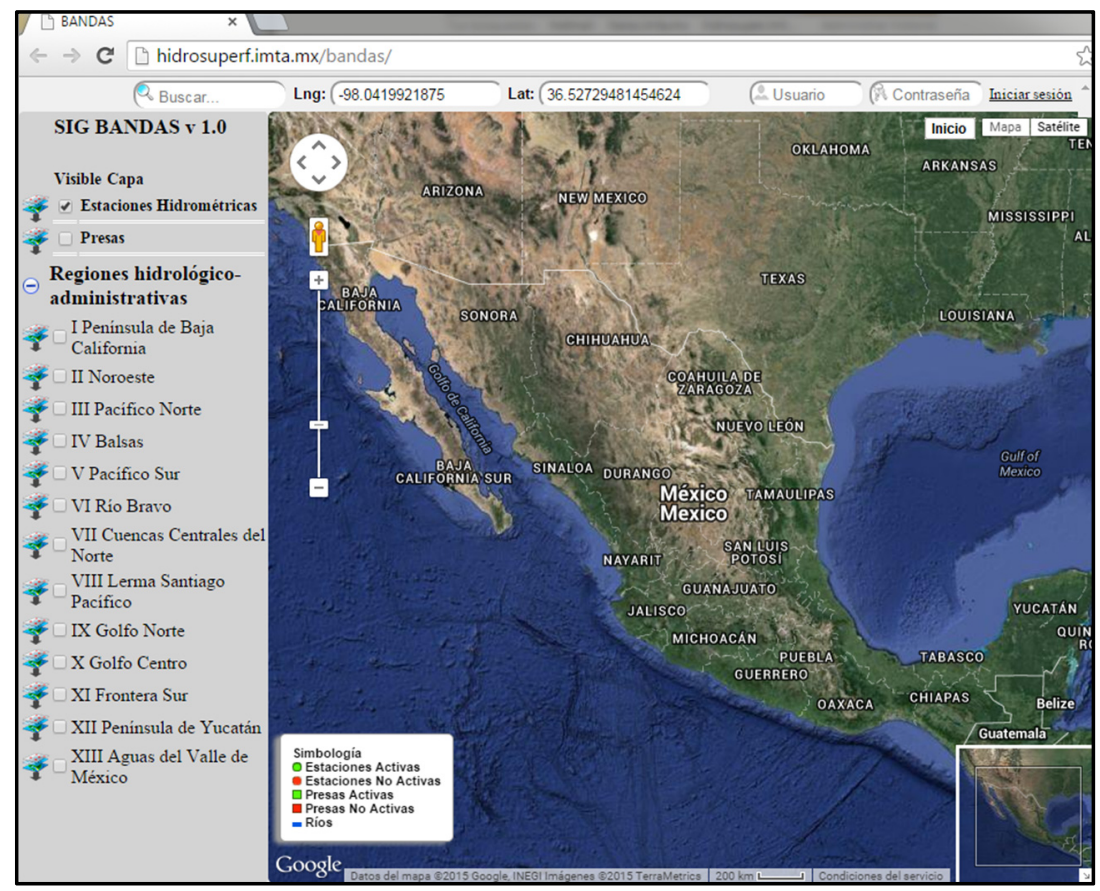

Figure 3: SIG Bandas's home screen.

To display the information from the inventory it is necessary to click on a green dot, as it is shown in Figure 5. It displays the CLAVE, name of the station, the period (years) recorded by the station, its basin, river, description of the location, kind or type of measurement, etc. at the end of this inventory box there are three option buttons: Images (imágenes), download historic data (Descargar historial) and descriptive record (Ficha descriptiva). 


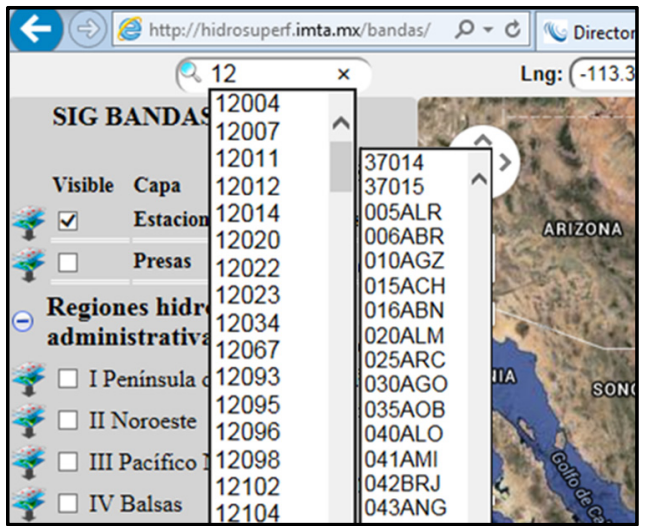

Figure 4: Search option to identify a specific station or dam.

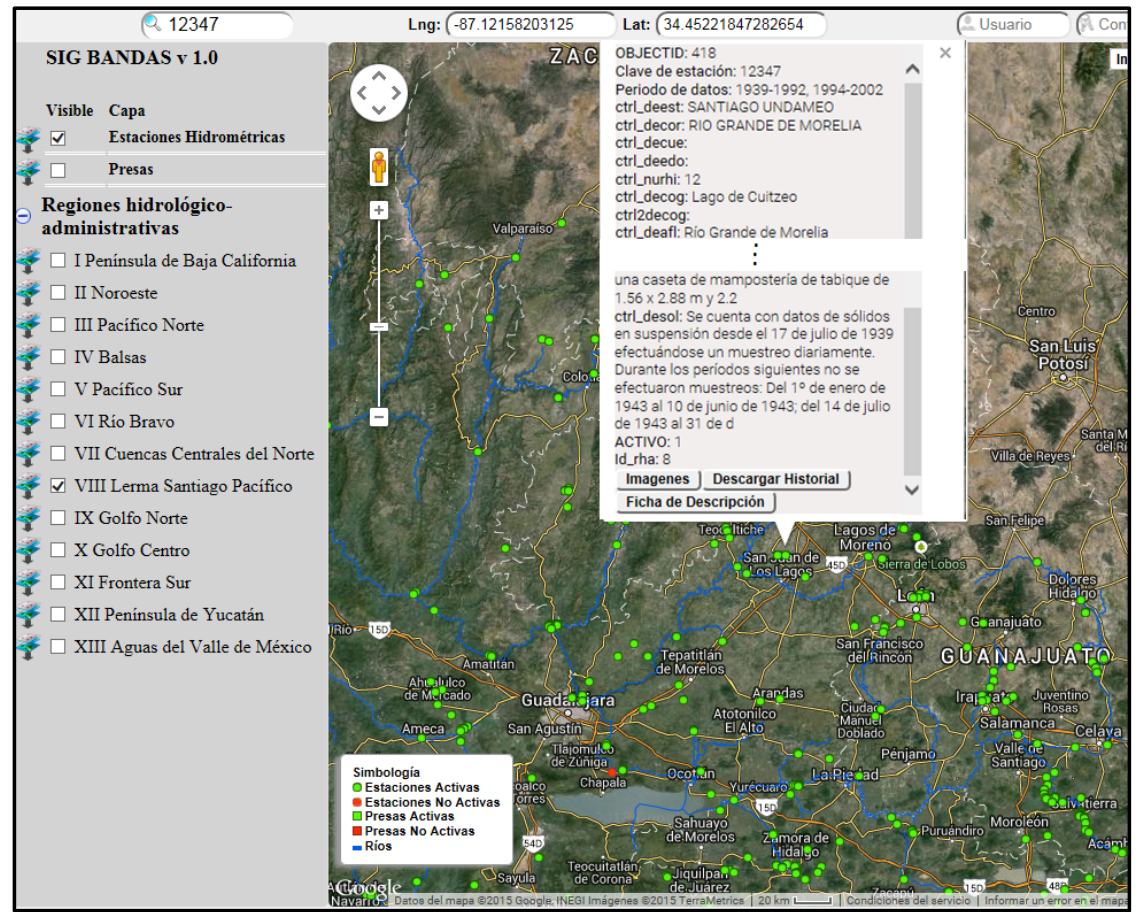

Figure 5: Zoom to a specific station and its inventory information.

Figure 6 shows an example about downloading a file containing data tables. The file downloaded is a Microsoft Access file (mdb file) its structure was described in section 2.1. In the same way it is possible to download all the shapes from each RHA, in order to use it in a Geographic Information System (GIS) as ArcGIS. 


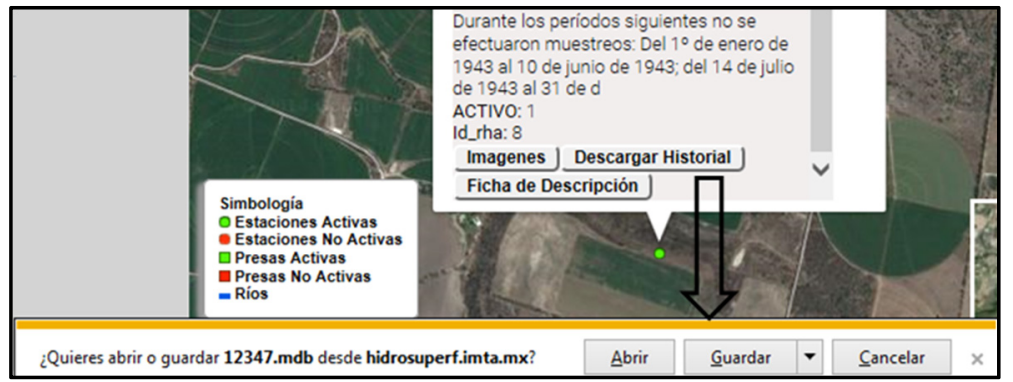

Figure 6: Download historic data from a specific station (example).

Likewise, it is possible to download the descriptive record which corresponds to a text file and it can be read for any text editor. Figure 7 shows the way to download this text file and display some parts of it in a notepad editor. As it can be seen, this descriptive record includes long name's station, larger key's station, coordinates (grades, minutes and seconds), location, purpose of its installation, path to reach it, information about the climatologic station near to the hydrometric station (if it exists), and some outstanding notes needed to know more about the station.

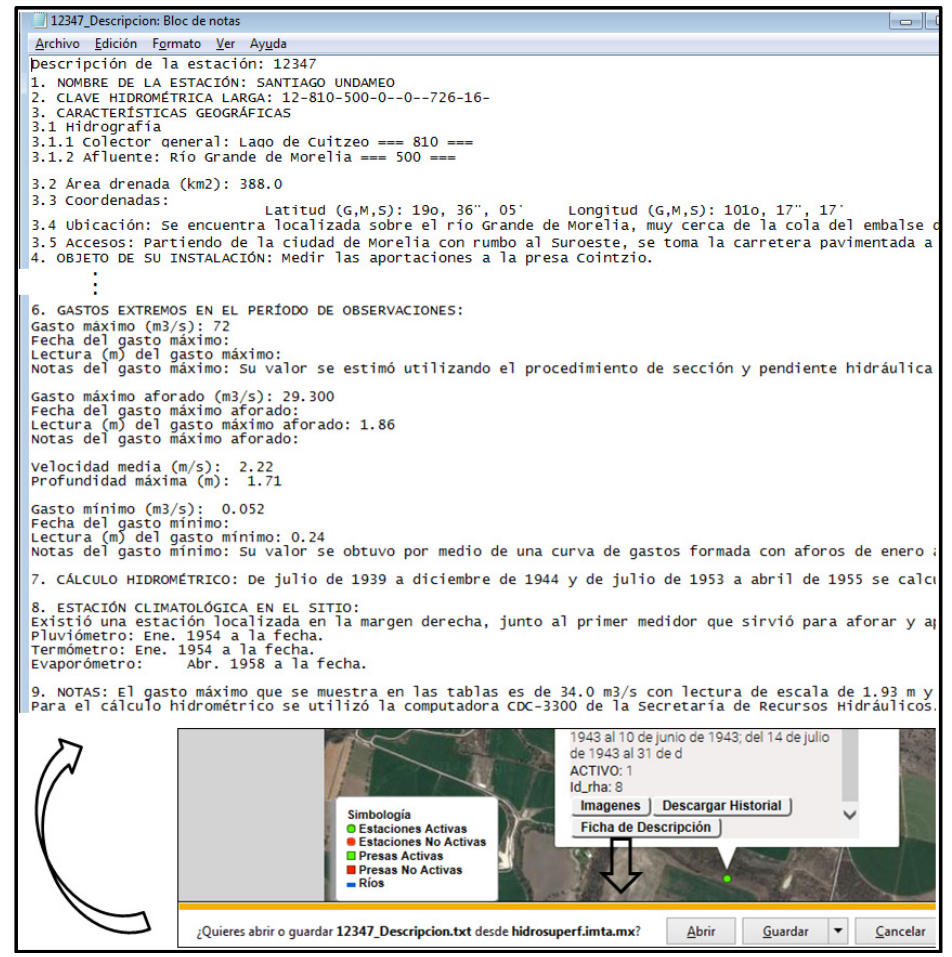

Figure 7: Download descriptive record data from a specific station (example). 
The last of the three buttons corresponds to the images button which allows the user to display an image or the number of images that exists in the hydrometric station SQL database. Figure 8 shows an example of this kind of display. It just displays jpg format images so far.

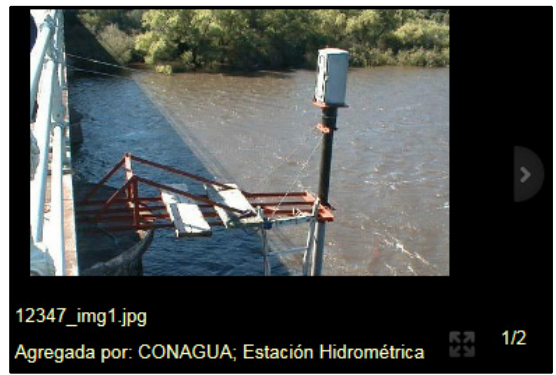

Figure 8: $\quad$ Button images from SIG Bandas v 1.0 (example).

Additionally, but only for users with password, SIG Bandas $v 1.0$ allows to update information on the hydrometric network. For administrator's users, SIG Bandas $v 1.0$ displays four buttons instead of the three previously described. The fourth button is called edition (editar). This tool was created due to the need of correcting the location of the hydrometric station having a map correctly georeferenced. This edition includes all the fields in the inventory, and also the possibility to erase a dot which represents a station or dam, add images and save all the changes.

Figure 9 shows an example of this edition record option, like station's key, period of time recorded by the station, its name, its basin, its sub-basin, its river, latitude and longitude coordinates, location description, path to get to it, runoff area, if the station is active or not, etc.

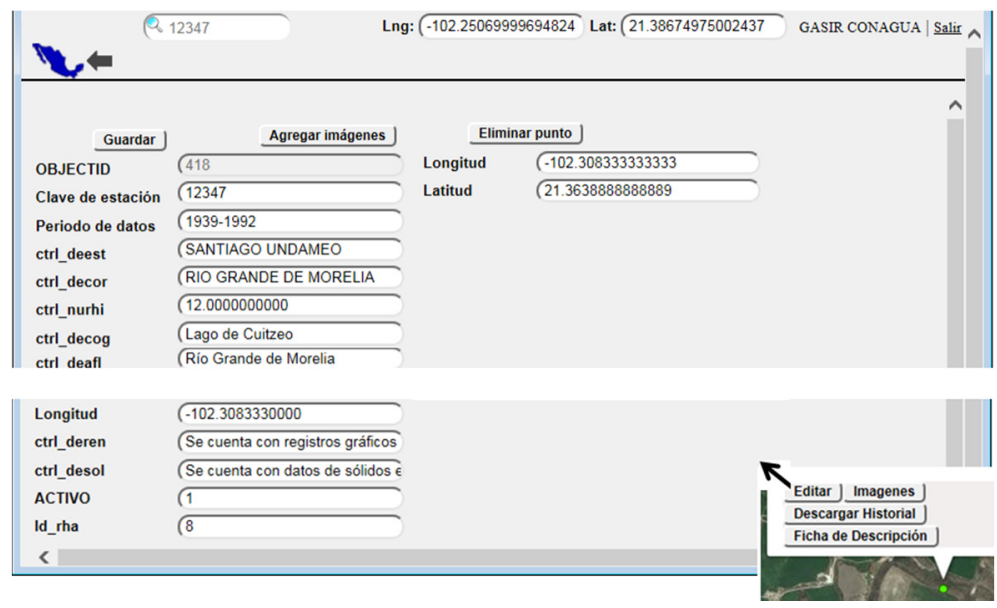

Figure 9: Edition button and edited fields (example). 
Once the user changes the coordinates, SIG Bandas $v$ 1.0, generates dynamically a new shape with this new edited information, and this is the way this national shape is always updated. Just Conagua's users are able to update this information.

\section{Conclusions}

We have a free tool which easily distributes measurement of the surface water from the main rivers in México, for many users such as, students from universities, consulting firms, government agencies, etc. As it was described, SIG Bandas v 1.0 filter stations and dams according to its hydrologic region (RH) or Administrative Hydrologic Regions (RHA) and using this base people are able to query just the stations or dams of their interest.

This tool was created during 2014, in the near future, it is going to be used to review, correct and update the database of all the hydrometric stations located in the country.

\section{References}

[1] IMTA-GASIR-Conagua. Banco Nacional de Datos de Aguas Superficiales. Informe final 2008. Anexo de formatos, pp. 1-50, 2008.

[2] IMTA-GASIR-Conagua. Manual del Banco Nacional de Datos de Aguas Superficial SIAS v1.0. México, pp. 1-150, 2008.

[3] Microsoft Developer Network (Asp.NET), https://msdn.microsoft.com/enus/library/System.Web.UI(v=vs.110).aspx

[4] Google developers (Google Maps API v3), https://developers.google.com/ maps/documentation/javascript/reference

[5] HTML(5) Tutorial, http://www.w3schools.com/html/

[6] JavaScript and HTML DOM Reference (JavaScript), http://www.w3schools.com/jsref/

[7] Microsoft Developer Network - Instrucciones de lenguaje de manipulación de datos (DML) (Transact-SQL) (SQL Server 2008), https://msdn.microsoft.com/es-es/library/ff848766(v=sql.105).aspx 